\title{
Host Genetics, Steatosis and Insulin Resistance among African Americans and Caucasian Americans with Hepatitis C Virus Genotype-1 Infection
}

\author{
A. Danielle luliano ${ }^{a}$ Eleanor Feingold ${ }^{b, c}$ Abdus S. Wahed ${ }^{c}$ David E. Kleiner ${ }^{f}$ \\ Steven H. Belle ${ }^{a, b}$ Hari S. Conjeevaram ${ }^{\mathrm{e}}$ Joseph Zmuda ${ }^{\mathrm{a}, \mathrm{b}} \quad$ T. Jake Liang ${ }^{\mathrm{g}}$ \\ Leland J. Yee ${ }^{a, d}$ for the Virahep-C Study \\ Departments of a Epidemiology, ${ }^{\mathrm{b}}$ Human Genetics, and ${ }^{\mathrm{c} B i o s t a t i s t i c s, ~ G r a d u a t e ~ S c h o o l ~ o f ~ P u b l i c ~ H e a l t h, ~ a n d ~}$ \\ dDivision of Infectious Diseases, Department of Medicine, School of Medicine, University of Pittsburgh, \\ Pittsburgh, Pa., ${ }^{e}$ Gastroenterology, University of Michigan, Ann Arbor, Mich., ${ }^{f}$ National Cancer Institute, and \\ ${ }^{g}$ Liver Diseases Branch, NIDDK, National Institutes of Health, Bethesda, Md., USA
}

\section{Key Words}

Steatosis $\cdot$ Insulin resistance $\cdot$ Hepatitis $C$ virus .

Host genetics

\begin{abstract}
Hepatic steatosis is the accumulation of fat in liver cells. Insulin resistance (IR) occurs when normal amounts of insulin do not stimulate insulin activity in cells. Both conditions have been described in hepatitis C virus (HCV) infection and are thought to be biologically related. This study examined the association of genetic variants with steatosis and IR among 167 African Americans and 184 Caucasian Americans with HCV genotype-1. Steatosis was defined as at least $5 \%$ of fat in cells on liver biopsy. IR was quantified as a score greater than 2 from the Homeostasis Model Assessment, version 2.2 (HOMA2-IR). Associations were investigated by estimating odds ratios separately by race. Statistically significant associations $(p<0.05)$ were observed for variants in interleukin-10 (IL10), leptin receptor (LEPR), interleukin-6 (IL6) and transforming growth factor beta-1 (TGF- $\beta 1$ ) for both outcomes. Some significant interactions were observed between IL10, LEPR and TGF- $\beta 1$ polymorphisms and HOMA2-IR scores when examining steatosis. The interaction of HOMA2-IR and IL10 was consistent in both races whereas for LEPR and TGF- $\beta 1$
\end{abstract}

the interactions were statistically significant in only one of the racial groups. These results could imply that some IL10, LEPR and TGF- $\beta 1$ polymorphisms may modify an association between steatosis and IR.

Copyright $\odot 2009$ S. Karger AG, Basel

\section{Introduction}

Hepatic steatosis is characterized by the accumulation of fat in the liver and diagnosis is generally made by the histological evaluation of liver biopsies and the quantification of the percentage of fat in liver cells [1]. The prevalence of steatosis has been reported to be as low as 30\% and as high as $84 \%$ among chronic hepatitis $\mathrm{C}$ virus (HCV) patients [2-6]. Steatosis occurs less frequently in the general population (31\%) compared to chronic HCV patients [7]. The mechanisms of hepatic steatosis are thought to be multifactorial and the presence of insulin resistance (IR) may be associated with the development of steatosis [8].

African Americans have a lower prevalence of steatosis than Caucasian Americans despite having a higher BMI, which is associated with steatosis, although the mechanisms are not fully understood $[7,9]$. Steatosis may

\section{KARGER}

๑ 2009 S. Karger AG, Basel

Fax +41 613061234

E-Mail karger@karger.ch

www.karger.com
Accessible online at:

www.karger.com/int
Dr. Leland J. Yee

A511 Crabtree Hall

130 DeSoto Street

Pittsburgh, PA 15261 (USA)

E-Mail yeel@edc.pitt.edu 
also adversely influence $\mathrm{HCV}$ sustained virologic response $[6,10,11]$. One study showed that HCV genotype1 patients with steatosis achieved sustained virologic response less frequently (40\%) compared to those without steatosis $(63 \%)$ [11].

IR is a condition in which normal amounts of insulin are insufficient to activate insulin function in cells, especially fat, muscle and liver cells, and which results in increased glucose levels $[12,13]$. IR may be quantified by the Homeostasis Model Assessment of Insulin Resistance index (HOMA-IR) [14]. Patients with chronic HCV infection were observed in one study to have higher HOMA-IR scores compared to healthy controls [15]. Factors associated with IR include African American race, obesity, older age, fibrosis and cirrhosis $[16,17]$. Presence of IR may negatively impact the function of interferon therapy and the ability to achieve sustained virologic response in $\mathrm{HCV}$ patients especially those infected with genotype-1 $[13,16]$.

In this study we hypothesized that genetic variants in collagen type-1 alpha-1 (COL1A1), cytochrome P450 2E1 (CYP2E1), interleukin-6 (IL6), interleukin-10 (IL10), interleukin-1 receptor type-1 (IL1R1), leptin receptor (LEPR), chemokine (C-C motif) ligand 2 (MCP1/CCL2), chemokine (C-C motif) ligand 8 (MCP2/CCL8), tumor necrosis factoralpha (TNF- $\alpha$ ) and transforming growth factor beta-1 (TGF- $\beta 1$ ) are associated with steatosis or IR in African Americans or Caucasian Americans infected with HCV genotype-1.

\section{Methods}

\section{Study Population and Clinical Data}

Data were from the Study of Viral Resistance of Antiviral Therapy of Chronic Hepatitis C (Virahep-C). Virahep-C design and primary outcomes have been described elsewhere [3]. Briefly, $401 \mathrm{HCV}$ treatment naïve patients were enrolled in the study, among whom 374 (194 Caucasian Americans and 180 African Americans) agreed to participate in the host genetics ancillary study and had DNA available for genotyping. Twelve individuals identified as Hispanic and 11 individuals using exogenous insulin were removed from analyses, resulting in a final sample size of 351.

Participants had a liver biopsy within 18 months of study enrollment $[3,18]$. Liver biopsies were scored by a single pathologist, who was blinded to patient outcome and clinical status $[3,18]$. Biopsies were assessed for the severity of hepatitis $\mathrm{C}$ by grading inflammation and staging of fibrosis using the modified histologic activity index scoring system [19]. Steatosis was also scored on a scale of $0-4$ according to the percentage of cells with fat [4]. For this study, IR was quantified by using the HOMA-IR calculator, version 2.2, released in 2004 and downloaded from www.dtu. ox.ac.uk $[20,21]$.
Single Nucleotide Polymorphism Selection and Genotyping

The genes examined were chosen from a list of genes already genotyped as part of the Virahep-C host genetics study. Although the original study selected candidate genes for their potential involvement in the response to therapy or liver fibrogenesis, a number of the targeted genes may also be involved with steatosis or IR and were included in the present study.

Two different approaches were utilized in the selection and genotyping of single nucleotide polymorphisms (SNPs) and were based on publically available genetic information and genotyping technology at the time each component was completed. The first method identified SNPs for IL6, IL10, TGF- $\beta 1$ and TNF- $\alpha$ and the subsequent genotyping by allelic discrimination is described elsewhere [18]. Briefly, SNPs were selected and allelic discrimination employing the ABI 7000 Sequence Detection System with TaqMan technology (Applied Biosystems Inc., Foster City, Calif., USA) was used to genotype the SNPs [18]. The second method for SNP selection and genotyping was utilized for COL1A1, CYP2E1, IL1R1, LEPR, MCP1/CCL2 and MCP2/CCL8. The SNP selection methods and genotyping using the Illumina BeadArray technology (Illumina, San Diego, Calif., USA) have been described elsewhere [22].

\section{Data Categorization}

Steatosis was dichotomized with those having at least $5 \%$ fat indicative of the presence of steatosis. For this study, IR was defined as a HOMA2-IR score greater than 2.0 based on a previous study from the Virahep-C cohort [4]. An a priori decision was made that if the less common homozygote genotype had a minor allele frequency of less than $5 \%$ it was combined with the heterozygote genotype.

Age, BMI, baseline viral level, weekly alcohol consumption, ALT levels, AST levels, cholesterol levels, triglyceride levels, modified histologic activity index score and Ishak fibrosis score (centered at their mean values), history of diabetes and HCV subtype were examined as potential risk factors for steatosis and IR. Steatosis was included as a predictor for IR, and IR was included as a possible risk factor for steatosis using the continuous natural log of HOMA2-IR scores centered at the mean. Self-reported race was used in this study due to a strong correlation between individual admixture and self-reported race [18].

\section{Genetic Analytical Methods}

Genotype and allele frequencies as well as Hardy Weinberg Equilibrium $\chi^{2}$ tests were calculated by race for each SNP. A genotype call rate, defined as the percentage of individuals where a genotype could be determined compared to the total number of individuals where genotyping was attempted, was calculated for each race group. Minor allele frequencies were examined by race for SNPs with a frequency greater than 5\%. The Tagger Program in the Haploview Software Suite version 4.0 was used to calculate the amount of variation accounted for in the gene $\left(\mathrm{r}^{2}\right)$ by the tagged SNPs separately by race [23]. This analysis was done to evaluate how well the SNP selection methods utilized for this study captured the common genetic variation compared to the more recently available HapMap Phase II data.

\section{Statistical Analyses}

Distribution of demographic characteristics and risk factors for steatosis and IR were compared between African Americans 
Table 1. Demographic characteristics by race

\begin{tabular}{|c|c|c|c|}
\hline & $\begin{array}{l}\text { African } \\
\text { American } \\
(\mathrm{n}=167)\end{array}$ & $\begin{array}{l}\text { Caucasian } \\
\text { American } \\
(\mathrm{n}=184)\end{array}$ & $\mathrm{p}$ value \\
\hline \multicolumn{4}{|c|}{$\begin{array}{l}\text { Demographic and lifestyle characteristics } \\
\text { Gender }\end{array}$} \\
\hline $\begin{array}{l}\text { Gender } \\
\text { Male }\end{array}$ & $107(64.1)$ & $118(64.1)$ & \\
\hline Female & $60(35.9)$ & $66(35.9)$ & $0.99^{\mathrm{b}}$ \\
\hline Age, years & $48.7(6.9)$ & $47.3(8.4)$ & $0.13^{\mathrm{a}}$ \\
\hline BMI & $30.8(6.4)$ & $28.2(5.2)$ & $<0.0001^{\mathrm{a}}$ \\
\hline $\begin{array}{l}\text { Alcohol consumption } \\
\text { units/week }\end{array}$ & $3.6(10.8)$ & $2.3(6.2)$ & $0.99^{\mathrm{a}}$ \\
\hline \multicolumn{4}{|l|}{ Laboratory measures } \\
\hline Triglycerides, mg/dl & $132.4(100.0)$ & $114.9(68.4)$ & $0.14^{\mathrm{a}}$ \\
\hline Cholesterol, mg/dl & $177.7(36.7)$ & $179.2(35.5)$ & $0.67^{\mathrm{a}}$ \\
\hline \multicolumn{4}{|l|}{ Measures of disease } \\
\hline $\begin{array}{l}\text { Baseline viral level, } \log _{10} \\
\mathrm{IU} / \mathrm{ml}\end{array}$ & $6.2(0.6)$ & $6.3(0.8)$ & $0.08^{\mathrm{a}}$ \\
\hline ALT, U/l & $70.6(45.8)$ & $108.0(91.5)$ & $<0.0001^{\mathrm{a}}$ \\
\hline AST, U/l & $60.0(43.2)$ & $73.0(58.7)$ & $0.06^{\mathrm{a}}$ \\
\hline \multicolumn{4}{|l|}{ Modified Histological } \\
\hline Activity Index & $10.0(3.2)$ & $10.4(3.5)$ & $0.21^{\mathrm{a}}$ \\
\hline Ishak fibrosis score & $2.1(1.4)$ & $2.3(1.5)$ & $0.33^{\mathrm{a}}$ \\
\hline \multicolumn{4}{|l|}{ Disease complications } \\
\hline \multicolumn{4}{|l|}{ Steatosis } \\
\hline No steatosis & $64(38.3)$ & $63(34.2)$ & \\
\hline Steatosis present & $103(61.7)$ & $121(65.8)$ & $0.43^{\mathrm{b}}$ \\
\hline \multicolumn{4}{|l|}{ Insulin resistance } \\
\hline HOMA $2<2$ & $83(58.5)$ & $104(66.7)$ & \\
\hline HOMA $2 \geq 2$ & $59(41.6)$ & $52(33.3)$ & $0.14^{\mathrm{b}}$ \\
\hline ln HOMA2-IR score & $0.6(0.7)$ & $0.4(0.7)$ & 0.006 \\
\hline
\end{tabular}

For categorical variables the frequency and percent are reported and for continuous variables the mean and standard deviation are reported. ${ }^{\mathrm{a}} \chi^{2}$ test. ${ }^{\mathrm{b}}$ Wilcoxon 2 -sample test.

and Caucasian Americans using appropriate association tests. Logistic regression was used and the log odds of the outcome (e.g. steatosis) were modeled as a linear function of the predictors. Models were adjusted for potential confounding variables and backward elimination was used to remove those that did not significantly contribute to the prediction of the outcome. Steatosis was retained in the model predicting IR because steatosis and IR are biologically related [24] and it is unclear if steatosis contributes to the occurrence of IR or vice versa.

Interactions between HOMA2-IR scores (when predicting steatosis) or steatosis (when predicting IR) and the genetic variant were tested, and the log likelihood ratio test was used to assess interactions. Nonsignificant ( $\mathrm{p} \leq 0.05$ ) interactions were not included in the model. Statistical significance was set at $\alpha=0.05$. The SAS ${ }^{\circledR} /$ STAT software system version 9.1.3 was used to complete analyses (SAS Institute Inc., Cary, N.C., USA).

Steatosis and Insulin Resistance in Hepatitis C

\section{Results}

\section{Population Characteristics}

Comparisons of demographic characteristics by race are shown in table 1 . There were 53 individuals who had missing data for HOMA2-IR because their insulin and glucose levels were not fasting or were not available because glucose or insulin levels were too high for the calculator.

Genotype frequencies, call rate and $p$ values from Hardy Weinberg equilibrium tests are provided in online supplementary table S1 (for all online supplementary material see www.karger.com/doi/10.1159/000214380). The selected SNPs for IL6, IL10, TGF- $\beta 1$ and TNF- $\alpha$ accounted for $38 \%(11-85 \%)$ of the common genetic variation in African Americans and 47\% (7-81\%) in Caucasian Americans. The selected SNPs for COL1A1, CYP2E1, IL1R1, LEPR, MCP1 and MCP2 accounted for 19\% (0-40\%) of the common genetic variation in African Americans and 39\% (16-83\%) in Caucasian Americans.

\section{Associations with Steatosis}

The final model for steatosis included BMI, weekly alcohol consumption, baseline viral level, Ishak fibrosis score and natural log transformed HOMA2-IR scores along with the genetic variant, and results for IL6, IL10, $L E P R$ and $T G F-\beta 1$ polymorphisms are reported in table 2. CYP2E1, IL1R1, MCP2/CCL 8 and TNF- $\alpha$ SNPs were not statistically significantly associated with steatosis. Haplotype analyses for the associations with steatosis yielded similar results to individual SNP analyses and are therefore not reported.

Caucasian Americans possessing the IL6 rs2069845AG or GG genotype had significantly higher odds of steatosis $(\mathrm{OR}=2.5,95 \% \mathrm{CI}=1.1-6.0)$ compared to those with the AA genotype (table 2). No significant associations were observed for this polymorphism in African Americans and the direction of the odds ratio was different. The odds of steatosis among African Americans with the TGF- $\beta 1$ rs $2278422-G G$ genotype were 4.4 times the odds of steatosis among African Americans with the CC or CG genotype and a similar, although non-significant, trend was observed among Caucasian Americans (table 2). A statistically significant interaction was observed in the prediction of steatosis between HOMA2-IR scores and $T G F-\beta 1$ rs 2241716 indicating that the relationship between steatosis and HOMA2-IR scores differs by genotype. Specifically, higher odds of steatosis were observed for a 1 unit higher HOMA2-IR score for African Americans possessing the TGF- $\beta 1$ rs2241716-GG genotype 
Table 2. Adjusted ORs for steatosis for selected SNPs and for the interaction between SNPs and HOMA2-IR among African Americans and Caucasian Americans

\begin{tabular}{|c|c|c|c|c|c|c|c|c|c|c|}
\hline & \multicolumn{5}{|c|}{ African Americans ${ }^{\mathrm{a}}(\mathrm{n}=167)$} & \multicolumn{5}{|c|}{ Caucasian Americans ${ }^{\mathrm{a}}(\mathrm{n}=184)$} \\
\hline & \multirow[t]{2}{*}{$\mathrm{n}$} & \multicolumn{2}{|l|}{ genetic variant } & \multicolumn{2}{|l|}{ HOMA2-IR ${ }^{b}$} & \multirow[t]{2}{*}{$\mathrm{n}$} & \multicolumn{2}{|l|}{ genetic variant } & \multicolumn{2}{|l|}{ HOMA2-IR } \\
\hline & & OR (95\% CI) & $\mathrm{p}$ & OR (95\% CI) & $\mathrm{p}$ & & OR $(95 \% \mathrm{CI})$ & $\mathrm{p}$ & OR $(95 \%$ CI $)$ & $\mathrm{p}$ \\
\hline \multicolumn{11}{|c|}{ IL6 rs 1880242} \\
\hline GG/GT & 52 & 1.00 & & \multirow{2}{*}{$2.11(1.18-3.79)$} & \multirow[t]{2}{*}{0.01} & 140 & 1.00 & & \multirow{2}{*}{$3.01(1.44-6.29)$} & \multirow[t]{2}{*}{0.003} \\
\hline TT & 115 & $1.28(0.57-2.89)$ & 0.55 & & & 43 & $0.78(0.29-2.06)$ & 0.61 & & \\
\hline \multicolumn{11}{|c|}{ IL6 rs2069837 } \\
\hline $\mathrm{AA}$ & 132 & 1.00 & & \multirow{3}{*}{$2.10(1.17-3.79)$} & \multirow{2}{*}{0.01} & 159 & 1.00 & & \multirow{2}{*}{$3.12(1.53-6.37)$} & \\
\hline AG/GG & 34 & $0.81(0.32-2.04)$ & 0.65 & & & 25 & $0.82(0.23-2.91)$ & 0.76 & & 0.002 \\
\hline \multicolumn{10}{|c|}{ IL6 rs2069845 } & \\
\hline AA & 75 & 1.00 & & \multirow[b]{2}{*}{$2.14(1.19-3.86)$} & \multirow[t]{2}{*}{0.01} & 60 & 1.00 & & \multirow[b]{2}{*}{$2.98(1.44-6.16)$} & \multirow[t]{2}{*}{0.003} \\
\hline AG/GG & 92 & $0.86(0.40-1.86)$ & 0.70 & & & 123 & $2.52(1.06-6.00)$ & 0.04 & & \\
\hline \multicolumn{11}{|c|}{ IL10 rs3024496 } \\
\hline CC & 28 & 1.00 & & $0.27(0.05-1.31)$ & 0.10 & 50 & 1.00 & & $1.46(0.52-4.15)$ & 0.47 \\
\hline CT & 82 & $2.02(0.64-6.36)$ & 0.23 & $3.39(1.31-8.78)^{\mathrm{c}}$ & 0.01 & 86 & $3.27(1.06-10.09)$ & 0.04 & $7.66(2.31-25.42)^{\mathrm{c}}$ & 0.001 \\
\hline TT & 57 & $3.98(1.15-13.77)$ & 0.03 & $2.24(0.80-6.28)$ & 0.13 & 48 & $1.69(0.48-5.92)$ & 0.41 & $9.30(1.45-59.53)^{\mathrm{c}}$ & 0.02 \\
\hline \multicolumn{11}{|c|}{ IL10 rs 1800890} \\
\hline $\mathrm{AA} / \mathrm{AT}$ & 70 & 1.00 & & \multirow{2}{*}{$2.16(1.20-3.88)$} & \multirow[t]{2}{*}{0.01} & 116 & 1.00 & & & 0.001 \\
\hline TT & 97 & $1.60(0.73-3.48)$ & 0.24 & & & 67 & $1.00(0.41-2.43)$ & 0.99 & $3.19(1.57-6.47)$ & \\
\hline LEPR rs 1137 & & & & & & & & & & \\
\hline AA & 112 & 1.00 & & & 0.01 & 100 & 1.00 & & $321-(158-654)$ & 0.001 \\
\hline AG/GG & 55 & $0.25(0.11-0.58)$ & $0.001\}$ & $2.25(1.22-4.15)$ & & 83 & $0.90(0.40-2.05)$ & $0.81\}$ & $3.21(1.58-6.54)$ & \\
\hline LEPR rs 1805 & & & & & & & & & & \\
\hline $\mathrm{CC}$ & 52 & 1.00 & & & & 74 & 1.00 & & $2.01(0.75-5.40)$ & 0.17 \\
\hline CT & 83 & $2.11(0.87-5.13)$ & 0.10 & & 0.01 & 70 & $4.36(1.21-15.73)$ & 0.03 & $29.60(4.27-205.2)^{c}$ & 0.001 \\
\hline TT & 32 & $0.63(0.21-1.90)$ & 0.42 & $2.38(1.30-4.35)$ & & 38 & $2.36(0.76-7.33)$ & 0.14 & $1.01(0.31-3.32)$ & 0.98 \\
\hline LEPR rs 1892 & & & & & & & & & & \\
\hline AA & 33 & 1.00 & & & & 40 & 1.00 & & $1.20(0.37-3.90)$ & 0.76 \\
\hline AG & 83 & $2.98(1.07-8.33)$ & 0.04 & & 0.01 & 69 & $1.79(0.45-7.16)$ & 0.41 & $26.22(3.81-180.4)^{c}$ & 0.001 \\
\hline GG & 51 & $1.55(0.52-4.62)$ & 0.43 & $2.35(1.28-4.30)$ & & 74 & $0.44(0.15-1.34)$ & 0.15 & $1.97(0.74-5.25)$ & 0.18 \\
\hline TGF- $\beta 1$ rs 22 & & & & & & & & & & \\
\hline $\mathrm{CC} / \mathrm{CG}$ & 85 & 1.00 & & & 0.001 & 130 & 1.00 & & & 0.001 \\
\hline GG & 82 & $4.42(1.84-10.65)$ & $0.001\}$ & $3.10(1.59-6.05)$ & & 54 & $1.50(0.62-3.60)$ & $0.37\}$ & $3.25(1.59-6.63)$ & \\
\hline TGF- $\beta$ rs 224 & & & & & & & & & & \\
\hline AA/AG & 16 & 1.00 & & $0.65(0.22-1.94)$ & 0.44 & 0 & 1.00 & & & \\
\hline GG & 151 & $1.48(0.47-4.62)$ & 0.50 & $3.34(1.61-6.91)$ & 0.001 & 183 & $\mathrm{~d}$ & & d & \\
\hline
\end{tabular}

$(\mathrm{OR}=3.3,95 \% \mathrm{CI}=1.6-6.9)$ compared to the odds for a 1 unit higher HOMA2-IR score among those with the AA or $\mathrm{AG}$ genotype $(\mathrm{OR}=0.7,95 \% \mathrm{CI}=0.2-1.9)$.

Statistically significant interactions between IL10 SNPs and HOMA2-IR scores were observed with respect to steatosis and seen in both Caucasian Americans and African Americans. The odds of steatosis for a 1 unit higher HOMA2-IR score for Caucasian Americans pos- sessing the IL10 rs3024496-CT (OR = 7.7, 95\% CI $=2.3-$ 25.4) or $\mathrm{TT}(\mathrm{OR}=9.3,95 \% \mathrm{CI}=1.5-59.2)$ genotype were significantly higher than the odds for a 1 unit higher HOMA2-IR score for those with the CC genotype $(\mathrm{OR}=$ 1.5, 95\% CI $=0.5-4.2$ ). In African Americans, the odds of steatosis for the IL10 rs3024496-CT genotype with a 1 unit higher HOMA2-IR score were higher (OR = 3.4, 95\% $\mathrm{CI}=1.3-8.8)$ compared to the odds for HOMA2-IR for 
Table 3. Adjusted ORs by selected SNPs and IR in African Americans and Caucasian Americans

\begin{tabular}{|c|c|c|c|c|c|c|c|c|}
\hline \multirow[t]{2}{*}{ SNP } & \multicolumn{4}{|c|}{ African Americans ${ }^{\mathrm{a}}(\mathrm{n}=142)$} & \multicolumn{4}{|c|}{ Caucasian Americans ${ }^{\mathrm{a}}(\mathrm{n}=156)$} \\
\hline & $\mathrm{n}$ & OR & $95 \% \mathrm{CI}$ & $\mathrm{p}$ & $\mathrm{n}$ & OR & $95 \% \mathrm{CI}$ & $\mathrm{p}$ \\
\hline \multicolumn{9}{|c|}{ IL6 rs1880242 } \\
\hline GG/GT & 45 & 1.00 & & & 119 & 1.00 & & \\
\hline $\mathrm{TT}$ & 97 & 1.06 & $0.47-2.39$ & 0.89 & 36 & 0.29 & $0.10-0.80$ & 0.02 \\
\hline \multicolumn{9}{|c|}{ IL6 rs2069837 } \\
\hline $\mathrm{AA} / \mathrm{AG}$ & 112 & 1.00 & & & 135 & 1.00 & & \\
\hline GG & 29 & 2.07 & $0.81-5.28$ & 0.13 & 21 & 0.24 & $0.06-0.88$ & 0.03 \\
\hline \multicolumn{9}{|c|}{ IL6 rs2069845 } \\
\hline AA & 63 & 1.00 & & & 52 & 1.00 & & \\
\hline AG/GG & 79 & 1.59 & $0.73-3.48$ & 0.24 & 103 & 1.70 & $0.75-3.85$ & 0.20 \\
\hline \multicolumn{9}{|c|}{ IL10 rs3024496 } \\
\hline $\mathrm{CC}$ & 20 & 1.00 & & & 44 & 1.00 & & \\
\hline CT & 70 & 0.26 & $0.08-0.82$ & 0.03 & 75 & 0.52 & $0.22-1.23$ & 0.14 \\
\hline $\mathrm{TT}$ & 52 & 0.41 & $0.12-1.41$ & 0.16 & 37 & 0.47 & $0.17-1.33$ & 0.16 \\
\hline \multicolumn{9}{|c|}{ IL10 rs 1800890} \\
\hline $\mathrm{AA} / \mathrm{AT}$ & 55 & 1.00 & & & 102 & 1.00 & & \\
\hline $\mathrm{TT}$ & 87 & 0.39 & $0.18-0.88$ & 0.02 & 53 & 0.65 & $0.29-1.43$ & 0.28 \\
\hline \multicolumn{9}{|c|}{ LEPR rs 1137100} \\
\hline $\mathrm{AA}$ & 93 & 1.00 & & & 88 & 1.00 & & \\
\hline AG/GG & 49 & 1.77 & $0.78-4.03$ & 0.17 & 67 & 1.44 & $0.69-2.98$ & 0.33 \\
\hline \multicolumn{9}{|c|}{ LEPR rs 1805096} \\
\hline $\mathrm{CC}$ & 44 & 1.00 & & & 62 & 1.00 & & \\
\hline CT & 68 & 0.65 & $0.27-1.60$ & 0.35 & 58 & 0.54 & $0.23-1.28$ & 0.16 \\
\hline $\mathrm{TT}$ & 30 & 1.88 & $0.65-5.44$ & 0.24 & 34 & 1.05 & $0.41-2.74$ & 0.91 \\
\hline \multicolumn{9}{|c|}{ LEPR rs 1892534} \\
\hline $\mathrm{AA}$ & 31 & 1.00 & & & 36 & 1.00 & & \\
\hline $\mathrm{AG}$ & 68 & 0.38 & $0.14-1.02$ & 0.06 & 57 & 0.57 & $0.22-1.50$ & 0.25 \\
\hline GG & 43 & 0.62 & $0.22-1.78$ & 0.38 & 62 & 1.00 & $0.39-2.57$ & 0.99 \\
\hline \multicolumn{9}{|c|}{ TGF- $\beta 1$ rs 2278422} \\
\hline $\mathrm{CC} / \mathrm{CG}$ & 76 & 1.00 & & & 111 & 1.00 & & \\
\hline GG & 66 & 0.38 & $0.17-0.89$ & 0.03 & 45 & 0.35 & $0.14-0.87$ & 0.02 \\
\hline \multicolumn{9}{|c|}{ TGF- $\beta$ rs 2241716} \\
\hline $\mathrm{AA} / \mathrm{AG}$ & 16 & 1.00 & & & 0 & 1.00 & & \\
\hline GG & 126 & 1.32 & $0.41-4.29$ & 0.64 & 155 & $\mathrm{~b}$ & & \\
\hline
\end{tabular}

Selected results are presented here, results for all SNPs available in supplementary online materials.

${ }^{a}$ Model adjusted for the genetic variant, centered Ishak fibrosis score, centered body mass index, steatosis, centered age and centered triglyceride levels.

${ }^{\mathrm{b}}$ Model could not be estimated because minor allele frequency $<5 \%$ for the SNP.

${ }^{\mathrm{c}}$ Homozygote genotype combined with heterozygote genotype to estimate association.

those with the CC genotype (OR $=0.3,95 \% \mathrm{CI}=0.1-1.3)$. In Caucasian Americans, the IL10 rs3024496-CT and TT genotypes have similar increasing log odds of steatosis and the CC genotype has more slowly increasing log odds of steatosis as the HOMA2-IR score increases. Individuals who possess the IL10 rs3024496-associated genotypes and have higher HOMA2-IR scores also have higher odds of steatosis compared to those with lower HOMA2-IR scores.

African Americans with the LEPR rs1137100-AG or GG genotype had $0.3(95 \% \mathrm{CI}=0.1-0.6)$ times lower odds of steatosis compared to those with the AA genotype (table 2). A similar, although nonsignificant, trend was observed for Caucasian Americans. African Americans 
possessing the LEPR rs1892534-AG genotype had triple the odds of having steatosis compared to those with the AA genotype (table 2). For a 1-unit increase in HOMA2IR score among Caucasian Americans, the odds of steatosis for LEPR rs1892534-AG genotype were 29.6 (95\% CI = 4.3-205.2) times greater compared to those with the AA genotype $(\mathrm{OR}=1.2,95 \% \mathrm{CI}=0.4-3.90)$. The odds of steatosis for a 1-unit higher HOMA2-IR score among Caucasian Americans possessing the LEPR rs1805096-CT genotype were significantly higher $(\mathrm{OR}=26.2,95 \% \mathrm{CI}=$ 3.8-180.4) than the odds for a 1-unit higher HOMA2-IR score among those with the CC genotype (OR $=2.0,95 \%$ $\mathrm{CI}=0.8-5.4)$. Results for SNPs not presented in table 2 are available in online supplementary table S2.

\section{Associations with Insulin Resistance}

No statistically significant SNP associations with IR were observed in either race group for COL1A1, CYP2E1, IL1R1, MCP1/CCL2, MCP2/CCL 8 or TNF- $\alpha$. Additional SNP results not described in table 3 are presented in the supplementary online tables. Haplotype analysis for the association with IR yielded results similar to those from individual SNP analyses and are not presented. No significant interactions between the genetic variants and steatosis contributed to associations with IR.

African Americans with the IL10 rs3024496-CT genotype $(\mathrm{OR}=0.3,95 \% \mathrm{CI}=0.1-0.8)$ or the $r s 1800890-\mathrm{TT}$ genotype $(\mathrm{OR}=0.4,95 \% \mathrm{CI}=0.2-0.9)$ had lower odds of IR compared to the rs3024496-CC genotype or the rs1800900-AA or AT genotype. A similar trend for these SNPs was observed among Caucasian Americans. Caucasian Americans with the IL6 rs1880242-TT genotype had 0.3 times lower odds of IR compared to Caucasian Americans with the GG or GT genotype. For TGF- $\beta 1$ $r s 2278422$, African Americans with the GG genotype had 0.2 times lower odds of IR (95\% CI $=0.2-0.9)$ and Caucasian Americans with the GG genotype had 0.4 times lower odds of IR (95\% CI $=0.1-0.9)$ compared to those with either the CC or CG genotype.

\section{Discussion}

This study investigated the association of host genetic markers with steatosis and IR for African American and Caucasian American patients with HCV genotype-1 infection. This study stratified all data by race as SNPs may have different effects in different ethnic groups based on their different population histories. Some associations identified in this study were only statistically significant in one race group or the direction of the association was different by race. One explanation may be that the associated genetic variants were not directly affecting the conditions, but rather were in linkage disequilibrium with functional genetic variants. If this were the case, the different patterns of results may be explained by different linkage disequilibrium patterns or the different population histories of African Americans and Caucasian Americans. For example, an associated SNP could be 'tagging' a causal genetic variant in one population that is not present in another population. Alternatively, different relatively new functional variants could lie on the same ancestral haplotype in different populations.

The findings from this study imply that some genetic variants may moderate or influence the association between steatosis and IR. For example, the association between steatosis and IR may be affected by IL10 rs3024496. Those with higher HOMA2-IR scores who possess the CT or TT genotype were more likely to also have steatosis compared to those with the CC genotype and higher HOMA2-IR scores. IL10 rs3024496 is located in the 3' untranslated region of the gene and has no known function [25]. Future work aimed at understanding the biological function of associated genetic variants may provide more information about how this genetic variant influences steatosis or IR.

For the LEPR gene, there were main effects associations of SNPs with steatosis or IR. The LEPR rs1137100AG or GG genotype was associated with lower odds of steatosis. Two statistically significant interactions were also observed between LEPR SNPs and HOMA2-IR scores with respect to steatosis in Caucasian Americans. LEPR rs 1137100 is located in the coding region and may contribute to splicing regulation [25]. LEPR rs1892534 is located in the $3^{\prime}$ downstream untranslated region with no known function [25]. Further understanding of the function of the associated genetic variants may explain the relationship with steatosis or IR in HCV infection.

There were statistically significant associations between TGF- $\beta 1$ SNPs and steatosis or IR indicating that polymorphisms in this gene may be important in understanding these conditions in HCV infection. In particular, possession of the TGF- $\beta 1$ rs $2278422-G G$ genotype indicated lower odds of IR for both race groups compared to the CC or CG genotype. TGF- $\beta 1$ rs 2278422 is located in the intron region with no known function [25]. In addition, one significant interaction was observed in African Americans between TGF- $\beta 1$ rs2241716-GG genotype and higher HOMA2-IR scores such that higher odds of steatosis were observed than expected for the main ef- 
fects of HOMA2-IR scores and the genotype alone. TGF$\beta 1$ rs 2241716 is located in the intron region and predicted to be an intronic enhancer which could change how the encoded protein is produced [25].

Future studies are needed to replicate our findings; however, a similar sample that included a sufficient number of African Americans was not available. Another limitation was the different methods utilized for selecting genetic variants. At the time the selection of SNPs was completed, HapMap Phase I was the main source of reference population data and was not able to identify SNPs to account for more of the common genetic variation observed in different racial groups. Thus, the amount of common variation characterized by the tag-SNPs selected is not as high as those expected by the second phase of HapMap which has the ability to better capture the common variation in the genes. Additionally, due to the hypothesis-generating nature of this study, adjustment for multiple comparisons was not completed and future studies are needed to confirm these findings. Nevertheless, our SNP results provide useful information about genetic variant associations with the conditions in $\mathrm{HCV}$ infection.

In conclusion, this study identified host genetic associations with steatosis or IR in African Americans and Caucasian Americans with HCV genotype-1. Significant associations between IL6, IL10, LEPR or TGF- $\beta 1$ and steatosis or IR were identified and the relationship between IR and steatosis may be moderated by genetic variants such as SNPs in the IL10 gene.

\section{Acknowledgments}

This clinical study was a cooperative agreement funded by the NIDDK and co-funded by the National Center on Minority Health and Health Disparities (NCMHD), with a Cooperative Research and Development Agreement (CRADA) with Roche Laboratories, Inc. Grant numbers: U01 DK60329, U01 DK60340, U01 DK60324, U01 DK60344, U01 DK60327, U01 DK60335, U01 DK60352, U01 DK60342, U01 DK60345, U01 DK60309, U01 DK60346, U01 DK60349, U01 DK60341. Other support for this study was from the National Center for Research Resources (NCRR), the Intramural Research Program of the NIH, National Cancer Institute, Center for Cancer Research, General Clinical Research Centers Program grants: M01 RR00645 (New York Presbyterian), M02 RR000079 (University of California, San Francisco),M01RR16500(UniversityofMaryland),M01RR000042 (University of Michigan), M01 RR00046 (University of North Carolina). Additional support was provided by 1KL2 RR02415401 (to Leland J. Yee) from the National Institutes of Health.

Members of Virahep-C contributing to the study include: from the Beth Israel Deaconess Medical Center, Boston, Mass.: Ne- zam Afdhal, MD (Principal Investigator), Tiffany Geahigan, PAC, MS (Research Coordinator); from the New York-Presbyterian Medical Center, New York, N.Y.: Robert S. Brown Jr, MD, MPH (Principal Investigator), Lorna Dove, MD, MPH (Co-Investigator), Shana Stovel, MPH (Study Coordinator); from the University of California, San Francisco, San Francisco, Calif:: Norah Terrault, MD, MPH (Principal Investigator), Stephanie Straley, PA-C, Eliana Agudelo, PA-C, Melissa Hinds, BA (Clinical Research Coordinator); from Rush University, Chicago, Ill.: Thelma E. Wiley, MD (Principal Investigator), Monique Williams, RN (Study Coordinator); from the University of Maryland, Baltimore, Md.: Charles D. Howell, MD (Principal Investigator), Karen Callison, RN (Study Coordinator); from the University of Miami, Miami, Fla.: Lennox J. Jeffers, MD (Principal Investigator), Shvawn McPherson Baker, PharmD (Co-Investigator), Maria DeMedina, MSPH (Project Manager), Carol Hermitt, MD (Project Coordinator); from the University of Michigan, Ann Arbor, Mich.: Hari S. Conjeevaram, MD, MS (Principal Investigator), Robert J. Fontana, MD (Co-Investigator), Donna Harsh, MS (Study Coordinator); from the University of North Carolina, Chapel Hill, N.C.: Michael W. Fried, MD (Principal Investigator,), Scott R. Smith, PhD (Co-Investigator), Dickens Theodore, MD, MPH (Co-Investigator), Steven Zacks, MD, MPH, FRCPC (Co-Investigator), Roshan Shrestha, MD (Co-Investigator), Karen Dougherty, NP (Co-Investigator), Paris Davis (Study Coordinator), Shirley Brown (Study Coordinator); from St. Louis University, St. Louis, Mo.: John E. Tavis, $\mathrm{PhD}$ (Principal Investigator), Adrian Di Bisceglie, MD (CoInvestigator), Ermei Yao, $\mathrm{PhD}$ (Co-Investigator), Maureen Donlin, PhD (Co-Investigator), Nathan Cannon, BS (Graduate Student), Ping Wang, BS (Lab Technician); from Cedars-Sinai Medical Center, Los Angeles, Calif.: Huiying Yang, MD, PhD (Principal Investigator), George Tang, PhD (Project Scientist), Dai Wang, PhD (Project Scientist); from the University of Colorado Health Sciences Center, Denver, Colo.: Hugo R. Rosen, MD (Principal Investigator), James R. Burton, MD (Co-Investigator), Jared Klarquist (Lab Technician); from Veteran's Administration, Portland, Oreg.: Scott Weston (Lab Technician); from Indiana University, Bloomington, Ind.: Milton W. Taylor, PhD (Principal Investigator), Corneliu Sanda, MD (Post-Doctoral Associate), Joel Schaley, $\mathrm{PhD}$ (Post-Doctoral Associate), Mary Ferris (Lab Assistant); from the Data Coordinating Center, Graduate School of Public Health at the University of Pittsburgh, Pittsburgh, Pa.: Steven H. Belle, PhD (Principal Investigator), Richard A. Bilonick, PhD (Statistician), Geoffrey Block, MD (Co-Investigator), Jennifer Cline, BS (Data Manager), Marika Haritos, MS (Statistician), KyungAh Im, MS (Statistician), Stephanie Kelley, MS (Data Manager), Sherry Kelsey, PhD (Co-Investigator), Laurie Koozer (Project Coordinator), Sharon Lawlor, MBA (Data Coordinator), Stephen B. Thomas, $\mathrm{PhD}$ (Co-Investigator), Abdus Wahed, $\mathrm{PhD}$ (Statistician), Yuling Wei, MS (Project Coordinator), Leland J. Yee, PhD (Consultant); from the National Institute of Diabetes and Digestive and Kidney Diseases: Patricia Robuck, PhD, MPH (Project Scientist), James Everhart, MD, MPH (Scientific Advisor), Jay H. Hoofnagle, MD (Scientific Advisor), Edward Doo, MD (Scientific Advisor), T. Jake Liang, MD (Scientific Advisor), Leonard B. Seeff, MD (Scientific Advisor); from the National Cancer Institute: David E. Kleiner, MD, PhD (Central Pathologist).

Intervirology 2009;52:49-56 55 


\section{References}

1 Teli MR, James OF, Burt AD, Bennett MK, Day CP: The natural history of nonalcoholic fatty liver: a follow-up study. Hepatology (Baltimore, Md.) 1995;22:1714-1719.

-2 Asselah T, Rubbia-Brandt L, Marcellin P, Negro F: Steatosis in chronic hepatitis C: why does it really matter? Gut 2006;55:123-130.

-3 Conjeevaram HS, Fried MW, Jeffers LJ, Terrault NA, Wiley-Lucas TE, Afdhal N, et al: Peginterferon and ribavirin treatment in African American and Caucasian American patients with hepatitis C genotype 1. Gastroenterology 2006;131:470-477.

$\checkmark 4$ Conjeevaram HS, Kleiner DE, Everhart JE, Hoofnagle JH, Zacks S, Afdhal NH, et al: Race, insulin resistance and hepatic steatosis in chronic hepatitis C. Hepatology 2007;45: 80-87.

5 Hui JM, Kench JG, Farrell GC, Lin R, Samarasinghe $\mathrm{D}$, Liddle $\mathrm{C}$, et al: Genotype-specific mechanisms for hepatic steatosis in chronic hepatitis C infection. J Gastroenterol Hepatol 2002;17:873-881.

6 Patton HM, Patel K, Behling C, Bylund D, Blatt LM, Vallee M, et al: The impact of steatosis on disease progression and early and sustained treatment response in chronic hepatitis C patients. J Hepatol 2004;40:484490.

7 Browning JD, Szczepaniak LS, Dobbins R, Nuremberg P, Horton JD, Cohen JC, et al: Prevalence of hepatic steatosis in an urban population in the United States: impact of ethnicity. Hepatology 2004;40:1387-1395.

$>8$ Adinolfi LE, Gambardella M, Andreana A, Tripodi MF, Utili R, Ruggiero G: Steatosis accelerates the progression of liver damage of chronic hepatitis $\mathrm{C}$ patients and correlates with specific HCV genotype and visceral obesity. Hepatology 2001;33:1358-1364.

$\checkmark 9$ Ruhl CE, Everhart JE: Epidemiology of nonalcoholic fatty liver. Clin Liv Dis 2004;8:501519, vii.
10 Fabris P, Floreani A, Carlotto A, Baldo V, Bozzola L, Giordani MT, et al: Impact of liver steatosis on virological response in [corrected] Italian patients with chronic hepatitis $\mathrm{C}$ treated with peg-interferon alpha-2b plus ribavarin. Aliment Pharmacol Ther 2005;21:1173-1178.

11 Westin J, Lagging M, Dhillon AP, Norkrans G, Romero AI, Pawlotsky JM, et al: Impact of hepatic steatosis on viral kinetics and treatment outcome during antiviral treatment of chronic HCV infection. J Viral Hepat 2007; 14:29-35.

12 Rao G: Insulin resistance syndrome. Am Fam Phys 2001;63:1159-1166.

13 Romero-Gomez M: Insulin resistance and hepatitis C. World J Gastroenterol 2006;12: 7075-7080.

14 Matthews DR, Hosker JP, Rudenski AS, Naylor BA, Treacher DF, Turner RC: Homeostasis model assessment: insulin resistance and beta-cell function from fasting plasma glucose and insulin concentrations in man. Diabetologia 1985;28:412-419.

15 Hui JM, Sud A, Farrell GC, Bandara P, Byth $\mathrm{K}$, Kench JG, et al: Insulin resistance is associated with chronic hepatitis $\mathrm{C}$ virus infection and fibrosis progression [corrected]. Gastroenterology 2003;125:1695-1704.

16 Romero-Gomez M, Del Mar Viloria M, Andrade RJ, Salmeron J, Diago M, Fernandez-Rodriguez CM, et al: Insulin resistance impairs sustained response rate to peginterferon plus ribavirin in chronic hepatitis $\mathrm{C}$ patients. Gastroenterology 2005; 128:636641.

17 Petit JM, Bour JB, Galland-Jos C, Minello A, Verges B, Guiguet M, et al: Risk factors for diabetes mellitus and early insulin resistance in chronic hepatitis C. J Hepatol 2001;35: 279-283.

18 Yee LJ, Tang YM, Kleiner DE, Wang D, Im K, Wahed AS, et al: Myxovirus-1 and protein kinase haplotypes and fibrosis in chronic hepatitis C virus. Hepatology 2007;46:7483.

19 Ishak K, Baptista A, Bianchi L, Callea F, De Groote J, Gudat F, et al: Histological grading and staging of chronic hepatitis. J Hepatol 1995;22:696-699.
20 Levy JC, Matthews DR, Hermans MP: Correct homeostasis model assessment (HOMA) evaluation uses the computer program. Diabetes Care 1998;21:2191-2192.

21 Wallace TM, Levy JC, Matthews DR: Use and abuse of HOMA modeling. Diabetes Care 2004;27:1487-1495.

22 Su X, Yee LJ, Im K, Rhodes S, Tang YM, Tong $\mathrm{X}$, et al: Association of single nucleotide polymorphisms in interferon signaling pathway genes and interferon stimulated genes with the response to interferon therapy for chronic hepatitis C. J Hepatol 2008;49:184191.

23 Barrett JC, Fry B, Maller J, Daly MJ: Haploview: analysis and visualization of $\mathrm{LD}$ and haplotype maps. Bioinformatics (Oxford, England) 2005;21:263-265.

24 Narita R, Abe S, Tabaru A, Otsuki M: Impact of steatosis on insulin secretion in chronic hepatitis C patients. Am J Gastroenterol 2007;102:2173-2180.

25 Yuan HY, Chiou JJ, Tseng WH, Liu CH, Liu CK, Lin YJ, et al: FASTSNP: an always up-todate and extendable service for SNP function analysis and prioritization. Nucleic Acids Res 2006;34(web server issue):W635-W641.

26 Cardellini M, Perego L, D’Adamo M, Marini MA, Procopio C, Hribal ML, et al: C-174G polymorphism in the promoter of the interleukin- 6 gene is associated with insulin resistance. Diabetes Care 2005;28:2007-2012.

$\checkmark 27$ Testa R, Olivieri F, Bonfigli AR, Sirolla C, Boemi M, Marchegiani F, et al: Interleukin6-174 G > C polymorphism affects the association between IL- 6 plasma levels and insulin resistance in type 2 diabetic patients. Diabetes Res Clin Pract 2006;71:299-305.

$\checkmark 28$ Yang X, Jansson PA, Pellme F, Laakso M, Smith U: Effect of the interleukin-6 (-174) $\mathrm{G} / \mathrm{C}$ promoter polymorphism on adiponectin and insulin sensitivity. Obes Res 2005;13: 813-817. 